
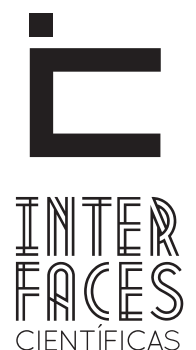

EDUCAÇÃO

ISSN IMPRESSO 2316-333X

ISSN ELETRÔNICO 2316-3828

DOI 10.17564/2316-3828.2016v4n3p159-168

\title{
DESATENÇÃO, HIPERATIVIDADE E IMPULSIVIDADE: REFLEXÕES CRÍTICAS SOBRE O TDAH
}

\author{
Dinamara Garcia Feldens ${ }^{1}$ \\ Barbara Távora Martins ${ }^{3}$ \\ Mary Barreto Dória ${ }^{5}$
}

\author{
Rafael Santos Barboza ${ }^{2}$ \\ Luana Garcia Fusaro ${ }^{4}$
}

\section{RESUMO}

A partir da importância adquirida pelas discussões sobre o transtorno do déficit de atenção com hiperatividade (TDAH) na contemporaneidade, este trabalho busca contribuir para que as reflexões acerca do tema não cessem ou se naturalizem. Discute-se, assim, a relação entre corpo, disciplinarização, escola e modos de subjetivação, com ênfase de investigação nas três categorias sintomáticas principais do TDAH: desatenção, hiperatividade e impulsividade. 0 referencial teórico-metodológico utilizado ampara-se nas relações de saber-poder trabalhadas por Foucault. Considera-se que a função do diagnóstico de TDAH envolve menos uma busca pela autonomia do sujeito frente a seu mal-estar e mais um mecanismo que captura a subjetividade do estudante, diminuindo as possibilidades de diferença no contexto escolar.

\section{PALAVRAS-CHAVE}

Psicopatologia, Contemporaneidade, TDAH, Escola, Disciplina. 


\section{ABSTRACT}

Considering the importance gained by the discussions about attention deficit hyperactivity disorder (ADHD) in contemporary times, this work aims to contribute to the reflections on the subject do not end or become established. It is discussed, therefore, the concept of body, disciplinarization, school and modes of subjectification, emphasizing the research in three main symptomatic categories of ADHD: inattention, hyperactivity and impulsivity. The theoretical and methodological framework used is sustained by the relations with knowledge and power developed by Foucault. It is considered that the role of diagnosis of ADHD involves less a search for the autonomy of the individual face to their suffering and more a mechanism that captures the subjectivity of students, reducing the possibilities of the differences in the school context.

\section{KEYWORDS}

Psychopathology, Contemporary, ADHD, School, Discipline.

\section{RESUMEN}

A partir de la importancia adquirida por las discusiones sobre el trastorno de hiperactividad con déficit de atención (TDAH) en la época contemporánea, este trabajo pretende contribuir de manera que las reflexiones sobre el tema no terminen o naturalizem. Se argumenta, por lo tanto, la noción de cuerpo, disciplina, la escuela y los modos de subjetividad, enfatizando la investigación en tres categorías principales síntomas del TDAH: falta de atención, hiperactividad e impulsividad. El marco teórico-metodológico utilizado se basa en las relaciones de saber-poder trabajado por Foucault. Se considera que la función del diagnóstico de TDAH implica menos una búsqueda de la autonomía del sujeto frente a su malestar y más un mecanismo que capta la subjetividad de los estudiantes, lo que reduce la diferencia de posibilidades en el contexto escolar.

\section{PALABRAS CLAVE}

Psicopatología, Contemporáneo, TDAH, Disciplina Escolar. 


\section{INTRODUÇÃO}

A partir da sintomatologia indicada para o Transtorno do Déficit de Atenção com Hiperatividade (TDAH), este trabalho busca problematizar questões ligadas à disciplina, à identidade e às articulações do saber-poder na esfera educacional, analisando processos de subjetivação operados na abordagem da psicopatologia no contexto atual.

Presente na mídia, em congressos de temáticas das mais variadas e no próprio cotidiano escolar e familiar, o chamado Transtorno do Déficit de Atenção com Hiperatividade (TDAH) adquiriu notoriedade nas discussões que contornam as chamadas patologias ou distúrbios da aprendizagem, que agrupa ainda diagnósticos específicos como a dislexia e a discalculia, entre outros. Benczik (2000), utilizando o referencial dos manuais psiquiátricos tradicionais, relata que a característica essencial do TDAH é "um padrão persistente de desatenção e/ou hiperatividade, mais frequente e severo do que aquele tipicamente observado em crianças de mesma idade que estão no nível equivalente de desenvolvimento" (p.25).

A quinta edição do Manual Diagnóstico e Estatístico de Transtornos Mentais da American Psychiatric Association (2014) reconhece dezoito sintomas entre categorias de Desatenção e Hiperatividade/Impulsividade. Até os dezesseis anos de idade, para que haja o diagnóstico é necessário que o indivíduo apresente o mínimo de seis sintomas, além da presença desses por pelo menos seis meses. Os mais velhos necessitam de apenas cinco sintomas para o enquadramento. Considera-se também o comprometimento social vinculado à patologia. Segundo Benczik, "as crianças com TDAH demonstram níveis de atenção inapropriados para a idade, são impulsivas e geralmente superativas, apresentam dificuldades para seguir regras e normas" (2000, p.26). Em resumo, possuem características totalmente opostas das fixadas pela instituição escolar consideradas propícias ao aprendizado adequado.
Por sua vez, o metilfenidato, substância mais conhecida pelo nome comercial de Ritalina, é destacada como um dos grandes salvadores dessa "bioidentidade patológica” (LIMA, 2005, p.18). De acordo com material jornalístico publicado em $2014^{1}$, o uso do medicamento aumentou $775 \%$ no Brasil nos últimos dez anos, segundo pesquisa feita pela Universidade Estadual do Rio de Janeiro. A ação do metilfenidato seria eficaz em razão da sua capacidade de regular substâncias neuroquímicas como a dopamina e a noradrenalina, de forma a estimular a concentração e a atenção do sujeito, diminuindo possibilidades de distração.

Em 2014 a Associação Brasileira do Déficit de Atenção elaborou uma carta aberta à população com o intuito de refutar a portaria de número 986/2014 da Secretaria Municipal de Saúde de São Paulo, que visava impor restrições à distribuição e ao acesso de medicamentos para o transtorno psiquiátrico. 0 argumento presente na carta considerava que a mudança "burocratiza o acesso digno ao tratamento, principalmente à população com desvantagem social, e se posiciona contra a sistematização científica de maneira mistificadora e indigna"2. Já o texto redigido para a portaria defende que "a prioridade do tratamento farmacológico leva frequentemente ao enfraquecimento das abordagens psicossociais necessárias tanto para 0 diagnóstico quanto a terapêutica"3. Considera ainda que o diagnóstico clínico do TDAH é complexo em razão de modelos escolares engessados e inadequados ao contexto da criança, além da existência de aspectos referentes às relações professor-aluno e entre os próprios colegas.

1. Matéria disponível em: http://www.ebc.com.br/infantil/para-pais/2014/09/uso-de-remedio-para-deficit-de-atencao-cresceu-775-em-10-anos. Acesso em 22 de Fevereiro de 2015.

2. Carta completa da Associação Brasileira do Déficit de Atenção disponível em: http://tdah.org.br/images/stories/pdfs/carta\%20aberta\%20 a\%20populacao\%20sobretdah.pdf. Acesso em 25 de Março de 2015.

3. Portaria de número $\mathbf{9 8 6 / 2 0 1 4}$ da Secretaria Municipal de Saúde da cidade de São Paulo disponível em: ftp://ftp.saude.sp.gov.br/ ftpsessp/bibliote/informe_eletronico/2014/iels.jun.14/lels110/M_PT-SMS-986_2014.pdf. Acesso em 16 de Março de 2015. 
No ano de 2010 a Associação Brasileira do Déficit de Atenção publicou o texto TDAH é uma doença inventada? ? $^{4}$ em seu portal oficial, problematizando a noção de que o transtorno não possui fundamentação científica ou mesmo que serve apenas para fins mercadológicos, com o intuito de incrementar a venda de medicamentos como a ritalina. A defesa se sustenta em seis pontos: 1) a presença e a discussão dos mesmos sintomas em períodos distantes da época moderna; 2) a observação de quadros similares ao do TDAH em países de contextos culturais diversos; 3 ) a recorrência dos portadores de TDAH a comorbidades como a depressão, ansiedade, abuso de drogas, além de acidentes, abandono escolar e desemprego; 4) a validação do transtorno pela Organização Mundial de Saúde; 5) o envolvimento genético envolvido em maiores taxas de prevalência; 6 ) o respaldo do meio científico em relação à existência e importância do transtorno.

Observando a complexidade do tema em questão, em consonância com a importância atual que essa discussão possui para a esfera educacional, elaboramos este trabalho com base na perspectiva teórico-metodológica de Michel Foucault, entre outros autores utilizados para trabalhar relações de poder e de subjetivação na nossa contemporaneidade. 0 recorte dado, por outro lado, não visa restringir ou monopolizar essa ampla discussão, tendo como objetivo principal a contribuição para que essas reflexões não sejam obturadas, mas continuem a brotar do espaço social.

\section{CORPO, SUBJETIVIDADE E PODER NA EDUCACÃO}

Entendemos que as subjetividades se deparam continuadamente com a paisagem do social ou com a "cartografia cultural que the serve de guia; e, reciprocamente, não há cultura sem um certo modo de subjetivação que funcione segundo seu perfil" (ROLNIK, 1997, p.40). Entender as tensões e marcas sociais que

4. Texto disponível em: http://www.tdah.org.br/br/textos/textos/ item/223-tdah-\%C3\%A9-uma-doen \%C3\%A7a-inventada?.html. Acesso em 20 de Fevereiro de 2015. habitam a instituição escolar, por esse pensamento, corresponde a um trabalho de cruzar as subjetividades presentes nessa esfera. Da mesma forma que pensar a subjetividade contemporânea nos leva a refletir sobre as tecnologias de saber-poder em movimento. Essa noção distancia-se do entendimento causal ou dialético entre sujeito e sociedade, permitindo-nos pensar que nem tudo está dado e para sempre (ROLNIK, 1997, p.42).

A perspectiva teórico-metodológica de Foucault utilizada no trabalho implica a ruptura com uma compreensão linear da historicidade, para se deslocar a um novo caminho que analisa o poder em sua "multiplicidade, nas suas diferenças, na sua especificidade, na sua reversibilidade: estudá-las, portanto, como relações de força que se entrecruzam" (Foucault, 1997, p.71). Isso significa que não se procura uma raiz ou origem da qual tenha derivado a questão atual do transtorno do déficit de atenção e hiperatividade na educação, do mesmo modo que não buscamos uma essência última que envolve a problemática e, então, a tudo explica. Para Foucault (1995, p.8):

\footnotetext{
É preciso despedaçar o que permitia o jogo consolante dos reconhecimentos. Saber, mesmo na ordem histórica, não significa reencontrar e sobretudo não significa reencontrar-nos. A história será efetiva na medida em que ela reintroduzir o descontínuo em nosso próprio ser. Ela dividirá nossos sentimentos; dramatizará nossos instintos; multiplicará nosso corpo e o oporá a si mesmo.
}

A escola, instituição moderna por excelência (SILVA, 2000, p.214), sabe a importância de um corpo dócil e controlado. Afinal de contas: "o controle da sociedade sobre os indivíduos não se opera simplesmente pela consciência ou pela ideologia, mas começa no corpo, com o corpo" (FOUCAULT, 1995, p.80).

Sobre o nascimento e as funções da instituição escolar:

A escola é uma instituição que nasce na Modernidade, com o objetivo de produzir um saber necessário ao poder disciplinar daquele contexto. Ela torna possível o 
mercado capitalista nascente e a solidez das ciências positivas, a partir da produção de signos, conceitos, valores morais e culturais que esta instituição produz e propaga. Produto de seu tempo e instituinte de si, a escola é uma instituição moderna. Ela reafirma as revoluções que a Modernidade gestou: a Revolução Industrial, no campo econômico, e a criação de um mercado que necessita de uma mão-de-obra disciplinada para a produção; a Revolução Francesa, no campo político, que instaura a democracia burguesa e, com ela, a idéia de uma escola para todos; o lluminismo, no campo das idéias, que passa a inaugurar uma razão científica positivista propagada pela escola em seus currículos e conteúdos programáticos; e o Renascimento, que, com seus valores estéticos e artísticos, estabelece a dicotomia entre a "boa arte", a erudição, a cultura erudita e a cultura popular (FELDENS, 2008, p.240).

Retomando Rolnik (1997), a pulverização das identidades no contexto mais contemporâneo não deixa de implicar na "produção de kits de perfis-padrão" (p.19). Temos assim o paradoxo atual da "desestabilização exarcebada de um lado e, de outro, a persistência da referência identitária, acenando com o perigo de se virar um nada, caso não se consiga produzir o perfil requerido [...]" (ROLNIK, 1997, p.20). Portanto, biopolíticas que produzem bioidentidades.

\section{ASANTÍSSIMATRINDADEDOTDAH:DESATENCC̄Õ, HIPERATIVIDADE E IMPULSIVIDADE}

A expressão "santíssima trindade" é mencionada por Rossano Lima em sua obra Somos Todos Desatentos? (2005, p.14), referenciando o termo usado pelo pesquisador Russel Barkley para designar os três principais sintomas do transtorno do déficit de atenção com hiperatividade, que engloba os demais: desatenção, hiperatividade, impulsividade. Para este trabalho desenvolveremos nossa pesquisa tendo como interesse essas três categorias sintomáticas, sob a hipótese de que elas são reveladores de contruções do saber e do poder em nossa sociedade, influenciando diretamente os modos de subjetivação na contemporaneidade e, indo mais além, funcionando como uma expressão desse funcionamento.
Em relação à desatenção, chama-nos a atenção a observação de Kastrup (2000, p.374)) sobre a ideia que se tem de progresso entre a passagem da vida infantil para o adulto, ou seja, como um período de preparação para as responsabilidades do adulto de pensar e conhecer. No entanto, "retraçar a marcha em direção à forma homem adulto de conhecer faz da criança uma forma negativa, prestes a ser ultrapassada [...]" (KASTRUP, 2000, p.381). A criança desatenta transforma-se naquela que desloca a sua concentração para outros modos de conhecer ou que busca outras maneiras de experimentar o mundo, diferentes do que é imposto pelo modelo pedagógico tradicional. Da mesma maneira, a negação e a rejeição do conteúdo que o aluno faz por meio da desatenção torna-se um dos indicativos de patologia a serem levados em consideração.

Outra crítica comum à patologização através do TDAH é que os sintomas enquadrados estariam em descompasso com os estímulos em excesso produzidos pela contemporaneidade. Segundo Buchianeri (2012) em sua pesquisa sobre a velocidade e o tédio no universo adolescente, ao sujeito em um contexto de hipervelocidade e instantaneidade cabe "mimetizar formas de ser, prontas e acabadas" (p.3). Exigir atenção e concentração para crianças e jovens, nesse contexto, seria assim um paradoxo, afinal, os próprios mecanismos sociais induzem à fugacidade e à superficialidade de pensamento.

Em uma de suas definições sobre o infantil, Kohan (2003) parece acentuar o aspecto enérgico e caloroso da criança, que em muitas situações não encontra lugar na disciplina do espaço escolar, geralmente adaptado para um tipo de subjetividade específica e binária: “[...] a infância é devir; sem pacto, sem falta, sem fim, sem captura; ela é desequilíbrio, busca; novos territórios; nomadismo; encontro; multiplicidade em processo, diferença, experiência (p. 253). Tal vida em movimento possui pouco espaço na imobilização das salas de aula.

Segundo Moraes (2012), as pesquisas sobre TDAH "dão a sensação de que o corpo infantil é escrutinado, dissecado, violado para se encontrar a causa de 
um comportamento anormal” (p. 305). A agitação do estudante, dessa forma, ganha uma localização específica no corpo sujeita às intervenções medicamentosas, através da regulação de neurotransmissores que, atuando em desequilíbrio, provocam a inadequação escolar, patologizável por trazer sofrimento ao sujeito. Pode-se perceber que a utilidade dos corpos está em jogo na questão do TDAH. Para que serve um corpo no espaço escolar que fantasia, que desterritorializa, que desordena as configurações pré-moduladas?

Destacamos ainda que o conceito de impulsividade - um dos três sintomas pertences à Santíssima Trindade do TDAH - nos rememora à própria questão da indisciplina escolar. A ação impulsiva é aquela que foge ao controle e aos filtros sociais. A indisciplina escolar desorganiza hierarquias, pois "tanto controle assim, era de se esperar, produz, no ato mesmo de controlar e com a mesma sutileza e dispersão, o seu contrário" (GUIRADO, 1996, p.66). O poder disciplinador e sua naturalização modulam as subjetividades com relevância no contexto educacional. Segundo Veiga-Neto (2011, p.110):

Enquanto uma ação violenta age apenas sobre um corpo, age diretamente sobre uma coisa, submetendo-a e a destruindo, o poder é uma ação sobre ações. Ele age de modo que aquele que se submete à sua ação o receba, aceite e tome como natural, necessário. Se na violência há dois pólos antagônicos - um sujeito que a pratica e um objeto que a sofre, cuja única alternativa é a resistência ou a fuga -, no poder não há propriamente dois polos, já que os dois elementos não são antagônicos, mas sim sujeitos num mesmo jogo.

O sintoma da indisciplina funciona como um dos principais indicadores da presença de uma produção de subjetividades reguladas em referência ao TDAH na educação. 0 devir-criança que nos habita produz linhas de desterritorialização que se contrapõe "à realização de tarefas requeridas no processo produtivo" (MORAES, 2012, p.46). A capilaridade do poder disciplinar penetra a paisagem coletiva da mesma forma que na subjetivação do sujeito, tornando-se naturalizada. Em meio a essas questões, a ordem escolar deve ser mantida, afinal de contas, a instituição continua sendo um espaço privilegiado para a preservação e perpetuação do saber-poder: “[...] não há relação de poder sem a constituição correlata de um campo de saber, nem saber que não suponha e não constitua, ao mesmo tempo, relações de poder” (FOUCAULT, 1995, p.30).

\section{CONSIDERAÇÕES FINAIS}

O discurso médico prevê uma desresponsabilização da subjetividade na criança, argumentando que, esses alunos, identificados negativamente como preguiçosos ou desleixados, agora podem se amparar nas armaduras da gramática científica, a qual concede um nome ao mal-estar. A pergunta que se faz, no entanto, é: quem cria esse mal-estar, do qual o estudante precisa se proteger? Para a perspectiva estritamente biológica: sinapses em má funcionamento, neurotransmissores em desequilíbrio, regiões corticais desestimuladas. Por outro lado, entendemos que essa visão facilita a predominância de mecanismos de docilização dos corpos e das subjetividades presentes no universo escolar, perpetuando ainda métodos pedagógicos inadequados à vivência infantil, que muitas vezes busca formas de resistência ao processo de padronização institucionalizado.

A questão do corpo é um traço em destaque na problemática do TDAH na educação, tanto pela tentativa de imobilizar esse corpo para fins de disciplina, como também em razão da via encontrada para essa docilização: a recorrência aos tratamentos farmacológicos que regulam os neurotransmissores. Talvez mais importante do que se questionar se o transtorno do déficit de atenção com hiperatividade existe ou não, pode ser mais profícuo se perguntar para que serve esse transtorno no contexto em que vivemos?

Levando em conta os jogos de saber e de poder operados, nesse quesito, pela psiquiatria e pelo dispositivo escolar, consideramos que o diagnóstico do TDAH envolve menos uma busca pela autonomia do 
sujeito frente a seu mal-estar e mais um mecanismo que captura a subjetividade do sujeito, diminuindo suas possibilidades de diferença e de multiplicidade.

\section{REFERÊNCIAS}

AMERICAN PSYCHIATRIC ASSOCIATION et al. Manual Diagnóstico e Estatístico de Transtornos Mentais-: DSM-5. Artmed Editora, 2014.

BENCZIK, E. B. P. Transtorno de déficit de Atenção. Casa do Psicólogo, 2000.

BUCHIANERI, L. G. C. Velocidade e Tédio: o paradoxo da adolescência no mundo contemporâneo. 119f. 2012. Tese (Doutorado em Psicologia) - Universidade Estadual Paulista-Faculdade de Ciências e Letras, Assis, 2012.

FELDENS, D. G. Os lugares da contemporaneidade e a escola de controle: cartografias do poder na educação. Educação Unisinos, v. 12, n. 3, p. 238-242, 2008.

FOUCAULT, M. Microfísica do Poder. Rio de Janeiro: Graal, 1995.

FOUCAULT, M. Resumo dos cursos do Collège de France (1970 - 1982). Rio de Janeiro: Jorge Zahar, 1997.

GUIRADO, M. Poder indisciplina: os surpreendentes rumos da relação do poder. In: AQUINO, J.G. (Org.).
Indisciplina na escola: alternativas teóricas e práticas. São Paulo: Summus Editorial, 1996. p. 57 a 72.

KASTRUP, V. 0 devir-criança e a cognição contemporânea. Psicologia: reflexão e crítica, v. 13, n. 3, p. 373-382, 2000.

KOHAN, W. O. Infância - Entre educação e filosofia. Belo Horizonte: Autêntica, 2003.

LIMA, C. Somos todos desatentos? O TDA/H e a construção de bioidentidades. Rio de Janeiro: Relume Dumará, 2005.

MORAES, R. B. de S. “...como se fosse lógico”: considerações críticas da medicalização do corpo infantil pelo TDAH na perspectiva da sociedade normalizada. 401f. 2012. Tese (Doutorado em Administração Pública e Governo) - Escola de Administração de Empresas de São Paulo da Fundação Getúlio Vargas, São Paulo, 2012.

ROLNIK, S. Uma insólita viagem à subjetividade: fronteiras com a ética e a cultura. 1997. Disponível em: <http://www.pucsp.br/nucleodesubjetividade/ Textos/SUELY/viagemsubjetic.pdf>. Acesso em: 10 de Janeiro de 2015.

VEIGA-NETO, A. Foucault \& a educação. Autêntica, 2003. 
1. Pesquisadora do Instituto Tecnológico de Pesquisa ITP, professora da Universidade Tiradentes -SE no Programa de Pós Graduação em Educação. É membro do Comitê Científico da Universidade Tiradentes e docente do Programa de Pós Graduação em Educação - Mestrado e Doutorado, coordena o Doutorado Interinstitucional/ DINTER em Educação. Atua principalmente nos temas: epistemologia do conhecimento, fundamentos da educação, gênero,ética,cultura, formação de professores, filosofias pós-modernas, contemporaneidade. Trabalha com os autores, Deleuze, Félix Guattari, Friedrich Nietzsche e Michel Foucault. Coordenadora do Grupo GPECS/UNIT/CNPQ.

2. Graduado em Comunicação Social (habilitação em Jornalismo) - Universidade Federal de Sergipe (UFS). Graduando em Psicologia - Universidade Tiradentes (UNIT). Bolsista de Iniciação Científica - PROBIC/UNIT. Pesquisador integrante do Grupo de Pesquisa "Educação, Cultura e Subjetividades" - GPECS, UNIT, CNPQ.

3. Graduada em Administração pela Universidade Tiradentes (2005). Pesquisadora integrante do Grupo de Pesquisa "Educação, Cultura e Subjetividades" - GPECS, UNIT, CNPQ.

4. Graduada em Comunicação Social (habilitação em Jornalismo) - Universidade Tiradentes (UNIT). Pesquisador integrante do Grupo de Pesquisa “Educação, Cultura e Subjetividades” - GPECS, UNIT, CNPQ.

5. Graduada em Pedagogia pela Universidade Estadual Vale do Acaraú (2006) e especialização latu sensu em Arte Educação pela Faculdade São Luis de França (2009), é mestre em Educação pela Universidade Tiradentes (UNIT) (Conceito CAPES 4) e membro do Grupo de Pesquisa em Educação, Cultura e Subjetividade (GPECS/UNIT/CNPq) 